\title{
The Construction of City Drainage Facilities Utility Model Based on the Method of Factor Analysis
}

\author{
$\mathrm{Xu} \mathrm{Min}^{1} \&$ Yanliang $\mathrm{Lu}^{1}$ \\ ${ }^{1}$ School of Social Science, Shanghai University of Engineering science, Shanghai, China \\ Correspondence: Xu Min, School of Social Science, Shanghai University of Engineering science, 333, Longteng Rd, \\ Shanghai 201620 P.R. China. Tel: 86-135-0160-3946. E-mail: xu_min109@126.com
}

Received: October 17, $2014 \quad$ Accepted: November 11, $2014 \quad$ Online Published: January 10, 2015

doi:10.5430/sass.v2n1p24 URL: http://dx.doi.org/10.5430/sass.v2n1p24

\begin{abstract}
Researching on urban drainage facilities from the perspective of utility, selection of utility evaluation method for the analysis of factor analysis method and AMOS software, according to the utility theory of value, it summarized the factors of influence drainage facilities utility, finally got 6 main factors and 16 secondary factors of affecting the city drainage facilities' utility, and to establish a set of scientific, systematic and operability of the utility value evaluation model of urban drainage facilities, to assess the objective value of utility of the urban drainage facilities.
\end{abstract}

Keywords: urban drainage, facilities construction, the utility model

Urban drainage facilities' good or not is an important sign to measure a city modernization level, not only related to People's Daily life, but also related to the overall image of the city. In theory, through the investigation and study on the present situation of city drainage facilities construction and its utility, is conducive to the utility model is applied to the city drainage facilities, and to verify the utility model of scientific and practical; In practice, it's helpful for in finding and solving the problems and shortcomings of the city drainage facilities construction, to the public, is to avoid the loss of the personal and property caused by poor drainage, and improve the quality of life, to the city, it's good for the construction of the drainage system to adapt international metropolis and the highly developed economy.

\section{The Influencing Factors of Urban Drainage Utility}

Proceed from the Angle of public drainage requirements, researching the influence factors of drainage utility, to explore the characteristics, advantages and disadvantages of urban drainage system, it becomes the key to the evaluation for the utility value of the urban drainage facilities from the point of view of economy.

From previous research and the practical analysis of the drainage facilities, the influence factors of urban drainage utility can be divided into the following several aspects.

Table 1. Experts and scholars on urban drainage impact factors on schedule

\begin{tabular}{cc}
\hline Factors affecting Experts & Experts \\
\hline The degree of Drainage facilities unobstructed & Zhi Huang \\
pre-planning & Yangshan Wu,Yunfei Huang \\
post-maintenance & Chen Zhang,Yan Chen \\
the drainage system & Cuihong Xu \\
The drainage condition & Ligang Su,Shuping Li \\
The utilization rate of emergency situations & Qiang Xue,Yaru Guan \\
\hline
\end{tabular}


By scholars and experts opinions before finishing and induction, and combined with their own ideas, the author thinks that the influencing factors of urban drainage effectiveness mainly have the following a few, the following process were expounded.

\subsection{The Public Satisfaction Index}

The public satisfaction index for drainage, is the important indicators of the evaluation of urban drainage facilities, this is determined by the utility theory basic content, in economics refers to the utility for consumers by consumption or enjoy leisure and so on to make their own needs, desires, get the satisfaction of the measurement. So for the construction of the urban drainage facilities, must according to the will of the public to provide drainage services, and let the citizen's satisfaction as a final standard to assess their utility. Therefore, for the measure of utility evaluation of urban drainage facilities, ultimately depends on the people are satisfied or not.

\subsection{The Degree of Drainage Facilities Unobstructed}

The degree of Drainage facilities unobstructed play to the role of the pilot Of urban drainage utility, the pros and cons of urban drainage facilities first depends on the degree of urban drainage unobstructed, a smooth drainage system in the fastest time free of urban rain water or sewage, the life and property of the public to obtain a good protection, but a drainage unobstructed, will cause the rain flow backward fester to polluting the environment.

\subsection{The Advanced of the Drainage System}

The urban drainage system refers to drainage system of different ways of life of urban sewage, industrial waste water and precipitation formed adopted. It can be divided into two types, namely combined and triage system. Pros and cons of urban drainage systems is directly related to how much to invest, the protect environment, as well as to play its own utility, but the decision of a regional drainage system is good or bad, incomplete drainage system is in its merits, but rather whether the system adapted to local circumstances, so choose a suitable urban drainage systems is essential.

\subsection{Effectiveness of Response to Unexpected Situations}

Under normal circumstances we are talking about the validity refers to the completion of planned activities and to the extent planned results. The effectiveness of urban drainage facilities to deal with unexpected situations refers to the use of urban drainage emergency measures to face the unexpected result of situations.

\subsection{The Drainage Condition}

Urban drainage facilities, including pre-planning and post- maintenance condition, both of them are related to the play of the urban drainage facilities utility. Pre-planning of urban drainage facilities should be based on the actual situation in the city where as a reference, while the city's drainage facilities basically completed, the building has the basic shape of the city-pattern, and then make a major surgery to the drainage, not only extremely difficult and expensive cost, will also be a long time-consuming, so urban drainage facilities maintenance measures must be done, so as to be truly optimal allocation of resources .

\subsection{The Extent of Demand for New Public Drainage Facilities}

The extent of demand for new public drainage facilities plays an important indicator to the utility of urban drainage facilities. The consumers' demand as the prerequisite and basis of the utility to be effective, if a consumer is no demand for a commodity, then the product for the consumer will not have effect. Similarly construction of urban drainage facilities, if the existing drainage facilities have been able to meet the needs of the public drainage, then the investing is not efficient, on the contrary, if the existing drainage facilities completely unable to meet the public drainage requirements, the construction of urban drainage facilities is necessary and have an effective use.

\section{Construction of Urban Drainage Facilities Utility Model}

\subsection{Constructed Conceptual Utility Model of the Urban Drainage Facilities}

By analyzing the influencing factors in the previous section on the urban drainage utility to play, Based on the existing theoretical results and empirical research data, this paper constructs a utility impact of urban drainage

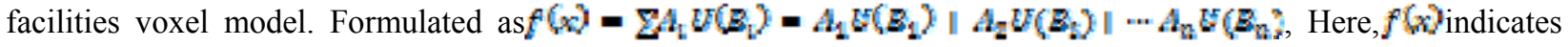
that a drainage facility total utility, $\boldsymbol{B}_{2} \cdot \boldsymbol{B}_{\mathbf{\alpha}} \cdot \boldsymbol{B}_{\mathrm{g}} \ldots \boldsymbol{B}_{n}$ stand for the influencing factors of the urban drainage utility. $A_{1}, A_{2} \ldots, A_{n_{2}}$, the index of evaluation utility, $f(x)=\Sigma A_{l} U\left(B_{0}\right)$ the total weighted utility and utility of each part. 


\subsection{The Analysis of Secondary Factors}

Utility model proposed in the article, the first use of the influencing factors analysis, the overall utility of urban drainage facilities is regarded as the dependent variable, it's influencing factors as independent variables. By using the Analytical Hierarchy Process, get a further subdivided to the influencing factors, so as to achieve the purpose of quantifiable data.

Table 2. Correspondence between the primary and secondary variables

\begin{tabular}{cc}
\hline Main variables & Sub variable \\
\hline The public satisfaction index & 1.Public living environment and environmental quality \\
2.Problems of drainage & 3.Drainage conditions \\
4he degree of Drainage facilities & 5.Public thought \\
unobstructed & 5. System Type \\
The advanced of the drainage system & 6. The service life of the drainage facilities \\
7. Management operation mechanism & 8. pre-planning \\
The drainage condition & 9. quality of basic amenities \\
10. post-maintenance \\
11. improvement way \\
12. financial support \\
The extent of demand for new public \\
drainage facilities
\end{tabular}

The main variables and secondary variables above represented by the letter, we can get the utility of urban drainage facilities route graph as follows:

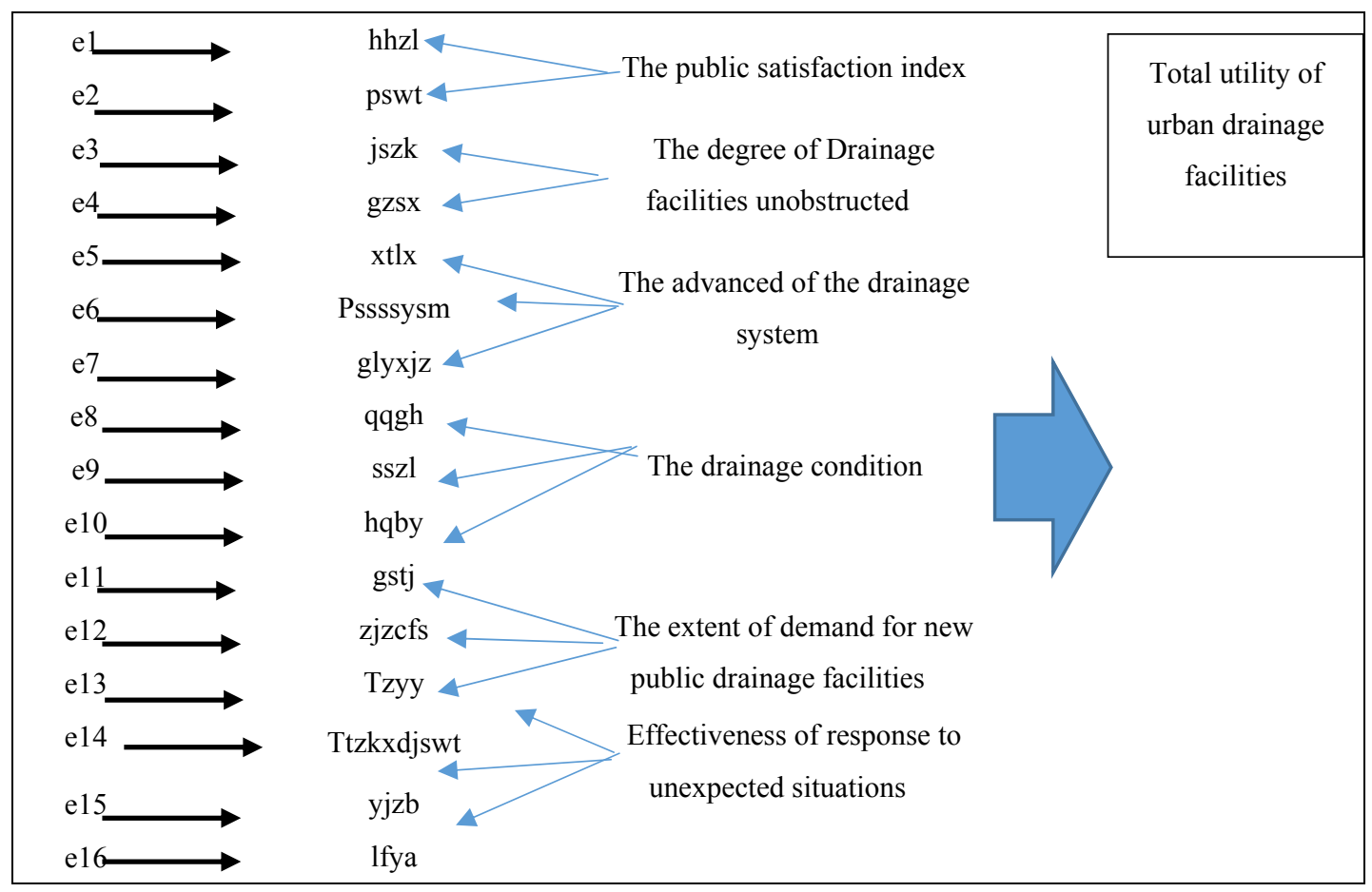

Figure 1. the utility of urban drainage facilities route graph 


\subsection{Evaluation and Testing of the Model}

The article first using SPSS statistical software entry for Shanghai questionnaire data and descriptive analysis, normality tests and other treatment, after using structural equation modeling statistical software AMOS select Maximum likelihood of sample data for analysis, the specific approach we using software do descriptive analysis and parameter estimation for the various factors.

\subsection{Descriptive Analysis and Fitting Test Model Sample}

By sorting data, the descriptive statistics for each sample project in Shanghai observed variables used herein are shown in Table 3. It can be seen that the mean, variance and other indices of the sample data in line with the actual situation.

Table 3. Descriptive analysis and normality test

\begin{tabular}{lllllll}
\hline Variable & min & max & skew & c.r. & kurtosis & c.r. \\
\hline hhzl & 0.000 & 31.000 & .016 & 0.176 & -1.315 & -3.653 \\
pswt & 2660.000 & 3700.000 & .325 & 2.783 & -0.143 & -0.535 \\
jszk & 4566.009 & 12455.000 & .279 & 2.651 & -0.098 & -0.465 \\
gzsx & 2.001 & 7.980 & .004 & 0.037 & -1.151 & -5.459 \\
xtlx & 62.000 & 110.000 & .695 & 2.633 & -1.021 & -4.653 \\
pssm & 0.000 & 1.000 & .134 & 3.455 & -1.546 & -5.452 \\
glyxj & 0.000 & 1.000 & .556 & 1.866 & -1.954 & -9.271 \\
qqgh & 0.000 & 1.000 & .652 & 0.365 & -1.289 & -5.458 \\
sszl & 0.000 & 1.000 & .580 & 5.500 & -0.070 & -0.334 \\
hqby & 30.000 & 30.100 & .655 & 4.747 & -0.070 & -0.648 \\
gstj & 56.000 & 56.000 & .135 & 3.200 & -1.335 & -5.230 \\
zjzzfs & 2.000 & 18.000 & .134 & 1.462 & -0.864 & -3.886 \\
tzyy & 0.000 & 7.900 & .635 & 3.864 & 1.651 & 7.834 \\
ttzkx & 0.000 & 1.000 & .562 & 4.71 & -1.321 & -3.907 \\
yjzb & 0.000 & 1.000 & .342 & 1.862 & -0.655 & -6.864 \\
lfya & 0.000 & 1.000 & .265 & 1.320 & -1.656 & -5.522 \\
Multivariate & & & & & 562.725 & 465.862 \\
\hline
\end{tabular}

\subsection{The Parameters of the Model Analysis}

As shown in Table 4, with maximum likelihood method to estimate the parameters of each regression coefficient results, in addition to a reference index value not estimated, the remaining regression weights have reached a significant level, 4 regression weights were significant in the model, which can also indicate good intrinsic quality of the model. 
Table 4. standardized regression coefficients

\begin{tabular}{|c|c|c|c|}
\hline Variable & $<---$ & Variable & Estimate \\
\hline hhzl & $<---$ & The public satisfaction index & 0.163 \\
\hline pswt & $<---$ & The public satisfaction index & 1.123 \\
\hline jszk & $<---$ & The degree of Drainage facilities unobstructed & 0.765 \\
\hline gzsx & $<---$ & The degree of Drainage facilities unobstructed & 0.782 \\
\hline xtlx & $<---$ & The advanced of the drainage system & 0.530 \\
\hline pssm & $<---$ & The advanced of the drainage system & 0.681 \\
\hline glyxj & $<---$ & The advanced of the drainage system & 0.371 \\
\hline qqgh & $<---$ & The drainage condition & 0.856 \\
\hline sszl & $<---$ & The drainage condition & 0.937 \\
\hline hqby & $<---$ & The drainage condition & 0.926 \\
\hline gstj & $<---$ & The extent of demand for new public drainage facilities & 0.341 \\
\hline zjzcf & $<---$ & The extent of demand for new public drainage facilities & 0.271 \\
\hline tzyy & $<---$ & The extent of demand for new public drainage facilities & 0.404 \\
\hline ttzkx & $<---$ & Effectiveness of response to unexpected situations & 0.712 \\
\hline yjzb & $<---$ & Effectiveness of response to unexpected situations & 0.603 \\
\hline Ifya & $<---$ & Effectiveness of response to unexpected situations & 0.245 \\
\hline
\end{tabular}

\subsection{The Empirical Result Analysis}

As can be seen from the table above, the public living environment and environmental quality of urban drainage facilities have a minimal impact on the utility, registering 0.163 , followed by legislative and financial support plans which are 0.245 and 0.271 , it can also be seen that from the table the biggest factor affecting the drainage facilities is the urban problems of drainage. From the pespective of the main variables as a whole, the main factor of the drainage condition should be the most important factor for urban drainage. Compared with other five main factors, it has the highest score, which precisely conforms to the case in reality: the condition of drainage facilities plays a decisive role in urban drainage utility.

As can be seen from Table 4, factors of pre-planning and post- maintenance represent 0.856 and 0.926 respectively, which is relatively high compared with the other factors. Thus, as for the pre-planning of urban drainage facilities, we need to achieve the "look ahead ", raise the planning standards, give adequate space for urban development in the future, be fully prepared to deal with unexpected situations of emergency for urban drainage, and do a good post-maintenance work for urban drainage facilities.

Results of this study indicate that the effect urban drainage facilities exert is not determined by a single factor, but as a result of a combination of factors. The total effect of the urban drainage facilities is a comprehensive and collective result of those factors. Among the various factors influencing the effectiveness of urban drainage facilities, the ones with the greatest influence on its total utility are its own situation and public satisfaction with the drainage facilities, which is decided by the definition of utility in economics and the value and use value of commodities. 


\section{Conclusion}

With the continuous development of urban economy and the growing prosperity, urban residents' demands for good drainage facilities are increasingly urgent in recent years, although the theoretical research on urban drainage facilities on the rise, but from the perspective of utility theory to analyze urban drainage facilities are almost none. Therefore, the article attempts to utility theory of value from the perspective of research and drainage facilities, through the establishment of a scientific, systematic, and have the utility value of urban drainage facilities operability evaluation model to assess the effectiveness of the objective value of urban drainage facilities. However, due to the author's views and perspectives may still omissions, I hope that the experts to give me some guidance.

\section{References}

Chen Zhang, \& Yan Chen. (2010). A higher starting point plan to construct urban drainage facilities. Shanghai Construction Science \& Technology, (02), 1-4.

Cuihong Xu. (2014). Urban drainage management system reform research. Jilin University, (04), 14-17.

Jun Wang. (2011). Improve drainage facilities planning to assure the safety of urban drainage. China's flood control and drought relief, (12), 29.

Ligang Su. (2009). Drainage countermeasure research of Changshu. Yangzhou University, (12), 16-23.

Qiang Xue. (2011). The development situation of tieling city drainage and objectives. Science and Technology Innovation Herald, (22), 118.

Shuping Li. (2002). Shallow discuss several problems in the city drainage system. China Municipal Engineering, (08), 53-55.

Yangshan Wu, Guangfan Shen, \& Yanxu Wang. (1989). China's urban drainage facilities cost - benefit analysis. China Water \& Wastewater, (03), 4-5.

Yangshan Wu, Yunfei Huang, \& Axing Wu. (1989). Talk about drainage construction investment through various means. China Water \& Wastewater, (03), 31-33.

Yanhong Gao. (2011). The western economic theory, (06), 56-57. The Chinese People's University Press.

Zhi Huang. (2008). Urban drainage facilities construction and urban sewage treatment. Science and Technology Innovation Herald, (17), 49. 